\title{
Carbon isotopic fractionation of carbon dioxide between gas and hydrate phases
}

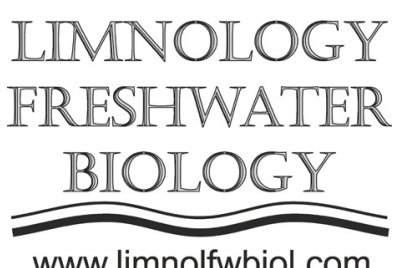

www.limnolfwbiol.com

\author{
Kimura H. ${ }^{1}$, Hachikubo A. ${ }^{1 *}$, Takeya $S .^{2}$ \\ ${ }^{1}$ Kitami Institute of Technology, 165 Koen-cho, Kitami 090-8507, Japan \\ ${ }^{2}$ National Institute of Advanced Industrial Science and Technology (AIST), Central 5, 1-1-1 Higashi, Tsukuba 305-8565, Japan
}

\begin{abstract}
During the formation of gas hydrate crystals, stable isotope fractionation of the guest molecules occurs. For methane and ethane, hydrogen stable isotope fractionation has been reported in the range of a few per mil, but for carbon stable isotope fractionation, there is no difference in $\delta^{13} \mathrm{C}$, or the difference is below the detection limit. As for carbon dioxide in natural gas hydrates, little is known about stable isotope fractionation of carbon dioxide. In this study, we report the stable isotope fractionation during formation of synthetic carbon dioxide hydrates under various temperature conditions. Fine ice powder and pure carbon dioxide gas were introduced into a pressure cell and adjusted to be above the equilibrium pressure of the hydrate and below the liquefaction pressure of the carbon dioxide at each temperature. After the formation of carbon dioxide hydrate, the residual gas was collected and the hydrate was recovered under the liquid nitrogen temperature to obtain the hydratebound gas. The carbon stable isotope ratios of carbon dioxide in the hydrate and residual gases were determined using a stable isotope mass spectrometer. Over a wide range from $243 \mathrm{~K}$ to $278 \mathrm{~K}$, the $\delta^{13} \mathrm{C}$ of residual gas was always larger than the hydrate phase, indicating that the carbon dioxide hydrate preferentially enclathrated lighter molecules. This trend is consistent with the results of a previous study. These results suggest that the equilibrium pressure of ${ }^{13} \mathrm{CO}_{2}$ hydrate is slightly higher than that of ${ }^{12} \mathrm{CO}_{2}$ hydrate.
\end{abstract}

Keywords: gas hydrate, carbon dioxide, isotopic fractionation, equilibrium pressure, isotopologue

\section{Introduction}

Most naturally occurring gas hydrates are methane hydrates, but natural $\mathrm{CO}_{2}$ hydrates also exist. The $\mathrm{CO}_{2}$ hydrate sample was observed at the Okinawa Trough, where $\mathrm{CO}_{2}$ seeps from the seafloor at a depth of $1335-1550 \mathrm{~m}$ and form crystals (Sakai et al., 1990). On the other hand, the possibility of $\mathrm{CO}_{2}$ hydrates in the polar caps of Mars has long been discussed (Miller and Smythe, 1970). Natural gas hydrates retrieved at Lake Baikal also contain small amount of $\mathrm{CO}_{2} \cdot \mathrm{CO}_{2}$ is one of the main components of natural gas, however, little has been known about $\mathrm{CO}_{2}$ as a guest gas of clathrate hydrate.

Since $\mathrm{CO}_{2}$ is composed of carbon and oxygen, there are several isotopic species of $\mathrm{CO}_{2}$ depending on the combination of stable isotopes (isotopologues: ${ }^{12} \mathrm{C},{ }^{13} \mathrm{C},{ }^{16} \mathrm{O},{ }^{17} \mathrm{O}$, and ${ }^{18} \mathrm{O}$ ). For example, the abundance ratio of ${ }^{13} \mathrm{CO}_{2}$ is about $1.1 \%$ of the total $\mathrm{CO}_{2}$, and the rest is almost ${ }^{12} \mathrm{CO}_{2}$. In geochemistry, the stable isotope ratio of carbon is used as an indicator of the origin of $\mathrm{CO}_{2}$ and related hydrocarbon gases. Luzi et al. (2011) first reported carbon stable isotope fractionation during the formation of $\mathrm{CO}_{2}$ hydrate, and revealed that the $\mathrm{CO}_{2}$ $\delta^{13} \mathrm{C}$ in the hydrate phase was $0.9 \%$ lower than that in the gas phase at $268 \mathrm{~K}$. This result indicates that ${ }^{12} \mathrm{CO}_{2}$ is more easily enclathrated in the hydrate phase than ${ }^{13} \mathrm{CO}_{2}$.

Stable isotope fractionation of the guest gas during the formation of gas hydrate is important information to discuss the formation, maintenance and decomposition processes of gas hydrate. In this study, $\mathrm{CO}_{2}$ hydrate was synthesized and stable isotope fractionation was detected over a wide range of temperatures.

\section{Material and methods}

Research grade carbon dioxide gas (99.999\%, Takachiho Chemical Industrial, but with a purity of about $99 \%$ as ${ }^{12} \mathrm{CO}_{2}$ ) was used as the guest gas. $\mathrm{CO}_{2}$ hydrates were formed at $243 \mathrm{~K}, 255 \mathrm{~K}, 258 \mathrm{~K}, 263 \mathrm{~K}$, $268 \mathrm{~K}, 273 \mathrm{~K}, 274 \mathrm{~K}$, and $278 \mathrm{~K}$. For the experiments below the ice point, $0.7 \mathrm{~g}$ of fine ice powder was filled in a pressure cell (volume: $30 \mathrm{~mL}$ ) and set in a cold room at $255 \mathrm{~K}$. For the experiment at $274 \mathrm{~K}, 5.3 \mathrm{~g}$ of distilled water was filled into another pressure cell (volume: 
$145 \mathrm{~mL}$ ) with a stirring device. After vacuuming the air in the cell at the temperature of liquid nitrogen, $\mathrm{CO}_{2}$ was introduced and controlled above the equilibrium pressure of $\mathrm{CO}_{2}$ hydrate and below the $\mathrm{CO}_{2}$ liquefaction pressure at each temperature. After the formation of the crystals, residual gas was collected and then the crystals were collected at the temperature of liquid nitrogen. For the residual gas, the sampling tube was connected to the vacuum line and the pressure of the sample $\mathrm{CO}_{2}$ was adjusted to the atmospheric pressure. The hydratebound gas was also obtained by dissociating the crystal in the vacuum line.

Each gas sample was introduced into a stable isotope mass spectrometer (Delta V, Thermo Fisher Scientific) by a syringe injection. The difference between the $\delta^{13} \mathrm{C}$ of the hydrate-bound gas and that of the residual gas $\left(\delta^{13} \mathrm{C}\right.$ of the residual gas $-\delta^{13} \mathrm{C}$ of the hydrate-bound gas, defined as $\Delta \delta^{13} \mathrm{C}$ ) was determined. A positive value of $\Delta \delta^{13} \mathrm{C}$ indicates that light $\mathrm{CO}_{2}$ (i.e. ${ }^{12} \mathrm{CO}_{2}$ ) prefers to be enclathrated.

\section{Results}

The $\mathrm{CO}_{2} \delta^{13} \mathrm{C}$ of hydrate bound gas was always 1.0-1.5\%o lower than that of the residual gas in a wide range of temperatures from $243 \mathrm{~K}$ to $278 \mathrm{~K}$. These results indicate that the hydrate phase tends to preferentially enclathrate ${ }^{12} \mathrm{CO}_{2}$. It also agrees with the previous work (Luzi et al., 2011) that reported 0.9\%o fractionation at $258 \mathrm{~K}$. The temperature effect on carbon stable isotope fractionation tended to increase slightly with decreasing temperature, but this is not yet certain, considering the error of stable isotope measurements.

\section{Discussion and conclusions}

In the case of methane stable isotope fractionation during the formation of methane hydrate showed little carbon stable isotope fractionation of methane (Hachikubo et al., 2007). On the other hand, the hydrogen stable isotope fractionation of methane has been detected and methane $\delta \mathrm{D}$ in the hydrate-bound gas is $4.8 \pm 0.4 \%$ smaller than that in the residual gas, suggesting that light $\mathrm{CH}_{4}$ is concentrated in the hydrate phase, while $\mathrm{CH}_{3} \mathrm{D}$ tends to remain in the gas phase.

These results can be explained by the difference in the equilibrium pressure of gas hydrate. The equilibrium pressure of $\mathrm{CH}_{3} \mathrm{D}$ hydrate is slightly higher than that of $\mathrm{CH}_{4}$ hydrate (Ozeki et al., 2018). It is easy to understand that methane is a mixture of isotopic species, even if they are the same methane. It is concluded that the difference in the equilibrium pressure of isotopologue gas hydrates causes the stable isotope fractionation of guest gases.

Applying the above discussion to the study of $\mathrm{CO}_{2}$ hydrate, it is expected that the equilibrium pressure of ${ }^{13} \mathrm{CO}_{2}$ hydrate was slightly higher than that of ${ }^{12} \mathrm{CO}_{2}$ hydrate according to the results of carbon isotope fractionation.

\section{Acknowledgments}

This work was partly supported by funding agencies in Japan (Japan Society for the Promotion of Science KAKENHI 26303021).

\section{References}

Hachikubo A., Kosaka T., Kida M. et al. 2007. Isotopic fractionation of methane and ethane hydrates between gas and hydrate phases. Geophysical Research Letters 34. DOI: 10.1029/2007GL030557

Luzi M., Schicks J.M., Erzinger J. 2011. Carbon isotopic fractionation of synthetic methane and carbon dioxide hydrates. In: 7th International Conference on Gas Hydrates (ICGH2011).

Miller S.L., Smythe W.D. 1970. Carbon dioxide clathrate in the Martian ice cap. Science 170: 531-533. DOI: 10.1126/ science.170.3957.531

Ozeki T., Kikuchi Y., Takeya S. et al. 2018. Phase equilibrium of isotopologue methane hydrates enclathrated $\mathrm{CH}_{3} \mathrm{D}$ and $\mathrm{CD}_{4}$. Journal of Chemical \& Engineering Data 63: 2266-2270. DOI: 10.1021/acs.jced.8b00203

Sakai H., Gamo T., Kim E-S. et al. 1990. Venting of carbon dioxide-rich fluid and hydrate formation in mid-Okinawa Trough backarc basin. Science 248: 1093-1096. DOI: 10.1126/science.248.4959.1093 